\title{
The Use of Direct Instruction Multiplication Flashcard and a Modified Math Racetrack Procedures on Mastery of Multiplication Facts for an At- Risk ${ }^{\text {th }}{ }^{\text {Grade Girl }}$
}

\author{
Gabrielle Rivera $^{1}$, Kalli Heric ${ }^{1}$, Randy L. Williams ${ }^{1}$, T.F. McLaughlin ${ }^{*}{ }^{1}$ and Gary Johnson ${ }^{2}$ \\ ${ }^{1}$ Department of Special Education, Gonzaga University, USA \\ ${ }^{2}$ St. Aloysius Catholic School, 611 E Mission Ave, Spokane, WA 99202, USA
}

\begin{abstract}
The purpose of this study was to evaluate the effects of the Direct Instruction (DI) flashcards procedure and the math racetrack to improve mastery of multiplication facts by a $6^{\text {th }}$ grade girl enrolled in a resource room classroom in a parochial school. The dependent variable was the number correct for multiplication facts. A second measure was the number of correct multiplication math facts from a pre- and posttest of 100 multiplication problems. The number of seconds required to complete the math racetrack was assessed. The effect of the DI flashcard procedure was evaluated in a single-subject multiple-baseline design between three sets of multiplication math facts. Our results indicated a clear functional relationship between the implementation of the DI multiplication flashcards and the mastery of multiplication facts with Sets 1 through 3. By the end of data collection, our participant had increased her performance on a 100problem, 5-minute, multiplication test from the pretest of 34 facts to the posttest of 55 facts.. The procedures were cost effective and required little training to implement.
\end{abstract}

Keywords: Classroom research, DI flashcards, math racetrack, multiple baseline design, parochial school, private school, sixth grade student.

\section{INTRODUCTION}

The Use of Direct Instruction Multiplication Flashcard and a Modified Math Racetrack Procedures on Mastery of Multiplication Facts for an At-Risk $6^{\text {th }}$ Grade Girl.

Skills in math are important for success in school as well as in adult life [1,2]. Knowledge of multiplication facts has been viewed as a critical skill needed to progress to more advanced stages of the mathematics curriculum [3]. Stein, Kinder, Silbert, and Carnine [4] define mastery of a basic fact as saying the entire statement and answer within 2 seconds. Mastery of math facts allows the student to focus on other critical components when solving more advanced math problems, such as story problems, and is imperative for success in K-12 math [4-6], as well as needed for functional living skills. At-risk students are students who are not considered to have a disability, but have a high chance of developing one [7]. The ability to be fluent in mathematics is important, because math is one of the basic skills needed to function well in society [1]. If a student is below grade level in math, it is more difficult for that student to attain mastery of other math concepts [8]. Students in the United States perform below average on math assessments compared to students in other countries [9].

The most prevalent evidenced-based intervention for children with deficiencies in math is systematic and explicit

*Address correspondence to this author at the Department of Special Education, Gonzaga University, Spokane, WA 99258-0025, USA;

Tel: (509) 313-3508; Fax: (509) 313-5965;

E-mails: mclaughlin@gonzaga.edu; tim.mclaughlin6@comcast.net instructions [10]. Direct Instruction (DI) employs guided instruction with a student. Direct Instruction has a long and large evidence based on its efficacy in general and special education $[10,11]$. With DI interventions, the student learns to apply the strategies used by effective learners in order to master concepts [10]. The procedure used for our participant in this study was a DI flashcards system and a math racetrack. Implementing DI flashcard system to teach basic math facts involves the following steps or procedures. First, a pretest is administered to determine which math facts the student knows or does not know. Second, these data are then employed to construct groups or sets of math facts that are then placed on flashcards. Third, a ratio of known to unknown facts found per set can vary. The use of known facts is employed to make sure that a student knows some facts while mastering the facts with that were missed on the pretest [10]. The student practices with an adult or another student going through the flashcards. When the student makes an error, a model, lead, and test (MLT) error correction procedure is employed. This involves the instructor saying the problem and its solution, followed by the instructor and student saying the math fact and it solution together. Finally, the student must answer correctly this fact independently. If the student still makes an error, this process is immediately applied again. When the student again makes the correct answer, that flashcard is placed two or three cards from the top of the stack of flashcards being taught. This is done to provide a student additional opportunities to practice errors their correctly. Finally, after the math problem that was initially missed had been independently answered correctly three times, this fact is placed at the bottom of that stack. 
Racetrack like procedures, often labeled reading or math racetracks, have been documented to be effective in helping students struggling with their basic skills [12-14]. Racetrack procedures have been shown to improve student performance in learning sight words [8, 15-17] and math facts [8, 18-22]. Racetracks require the construction of an oval track with 28 blank rectangles. Several samples of these racetracks can be found elsewhere [12, 14]. A math fact written either vertically or horizonally in each rectangle. Typically, the number of facts on a racetrack may vary, but 28 squares are typically constructed per track $[12,14]$. These problems are also placed on the racetrack randomly to prevent memorization facts using the order of how they are placed on the racetrack. Also, no two similar facts are placed such as $3 \times 2=\mathrm{N}$ or $2 \times 3=\mathrm{N}$ are placed next to one another. When the child makes an error going around the track, that math fact is noted and the MLT error correction procedure is carried out. After the student has gone through math facts placed on the racetrack two times, he or she is then timed for one minute. The student is to answer the problems and its solution as fast and as far around the track as possible in one minute. Data from this 1-minute timing then plotted on a line graph by the student or instructor. This is done to provide the student with a visual record of his or her performance. After four school days on a particular track or if the student has been $100 \%$ accurate for three days in a row, a new track is employed. In addition, after every fifth racetrack there a review track is required. This review track contains the math problems from the previous four tracks [8, 18-22]. Racetracks can be implemented using other students, instructional assistants, or teachers as instructors. Finally, flashcards are often employed as part of a racetrack procedure before the 1-minute timing takes place $[19,20]$.

The purpose of this study was to evaluate the effects of the DI multiplication flashcards system and a modified math racetrack on mastery of multiplication facts by an at-risk $6^{\text {th }}$ grade girl. Likewise, such an evaluation would provide a replication $[23,24]$ by employing DI flashcards and a math racetrack in math in a parochial school setting. This should increase the confidence for teachers to implement and employ DI flashcards and racetrack procedures in their respective classrooms.

\section{METHOD}

\section{Participant and Setting}

Our participant was a sixth-grade girl who was working at a fifth-grade level in mathematics. She was social, but had difficulty remaining on task. She participated during mathematical activities and practice, but often asked for assistance with her assignments. She had a younger sister who had difficulty in math as well. Our participant was enthusiastic about learning and applying her math skills. However, she became easily discouraged when faced with a problem for which she could not answer.

The study took place in a special education resource room in a K-8 Catholic school located in a large urban city in the Pacific Northwest. The resource room focused on improving math skills and other academic issues for which the student or students were experiencing. All the students placed in this class, spent at least one hour each school day in the resource room. The classroom goal for the classroom was to create a more intimate environment where these students could receive additional one on one instruction and help. The number of students enrolled in this resource room varied form 10 to 12 fifth and sixth grade students. Data were gathered twice each week during mid-morning on every Tuesday and Thursday.

\section{Response Definition and Observation Procedures}

The first dependent variable was the number of multiplication problems. These data were collected from a 100 -problem pre-and post-test. The second measure was student accuracy with 21 unmastered multiplication facts each session. These facts were divided into three separate sets. Each problem was placed on a single flashcards. The participant was required to orally answer the fact in two seconds or less. These cards were presented at the beginning of each session and student accuracy was recorded. If the child stated the fact correctly within 2 seconds, it was recorded as correct. If the student stated the fact and solution incorrectly, provided no answer, or answered the problem in more than 2 seconds, it was defined as an error. For each session, only the problems that our participant missed on the pretest were counted. The seven math facts that our participant knew on the pretest were also placed in each set. This was done to reduce the probability of our participant being discouraged or giving up. The time to complete the math racetrack was also taken. This was done by the first or second author noted the time needed to complete the first math racetrack each day. These data were recorded in seconds.

\section{Experimental Design and Conditions}

A single-subject, multiple baseline design [23, 24] across three sets of target multiplication facts was used to determine whether the DI flashcards along with the math racetrack was effective at promoting the child's mastered target multiplication facts. A written pre- and post-test was employed to evaluate the student's mastery of her basic multiplication facts.

Pretesting and baseline. Prior to intervention, the child was presented with a basic multiplication pre-test to document which multiplication facts our participant did or did not know. Based on this pretesting, our participant was evaluated each session on the 21 multiplication flashcards she had missed from the pretest. During the three baseline conditions, our participant was not provided with any feedback as to her performance. Baseline was in effect for 3 to 13 sessions or school days.

DI flashcards with a modified math racetrack. The DI flashcard procedure was used in combination with contingent praise from the first two authors. A set of seven flashcards that were unmastered facts was combined with seven previously mastered facts and was presented to the student. Each flashcard was presented and the student had to repeat the fact and the correct answer within 2 seconds in order for that flashcard to be moved to the back of the deck. In addition, the researcher presented praise contingent upon the student's correct answer. If the student answered the fact incorrectly or took more than 2 seconds, the authors modeled the correct problem and its solution. Next, the student and instructor jointly orally say the problem and its solution 
together. The next step requires the student to say the fact and its correct solution. Finally, the card is placed back only 2 cards back from the top of the deck. Once the student responds correctly three times, the card is placed at the bottom of the deck. This procedure continues for approximately 10 minutes. The first two authors then placed these 14 flashcards, seven mastered and seven target facts, on the desk in rows in no particular order. The student is then timed to see how fast she could say the multiplication fact with the correct answer following the rows of flashcards. If the child answered a fact in error, one of the first two authors modeled saying the fact with the correct answer. The participant was required to repeat the solution and its correctly, and then allowed to move to the next fact. Once the student completed the math timing, she was encouraged to try again for a faster time the next occassion she was assessed. This whole procedure took approximately 15 minutes to carry out.

\section{Reliability of Measurement}

Interobserver reliability was conducted once during baseline and five times during the intervention. One of the researchers held up the flashcards for the student and recorded data at the same time while the other researcher observed and recorded data as well. The researchers sat such that the other's recording form could not be seen to ensure independence of the recordings. Both the researchers were noting whether the student stated the entire fact correctly within 2 seconds. A "+" was marked if the child stated the fact within 2 seconds or if she was able to correct her statement within that 2 seconds. A "-" was marked if the child stated the fact incorrectly or took longer than 2 seconds to respond. The percent of interobserver agreement was calculated by dividing the number of agreements by the number of agreements plus disagreements multiplied by 100 . The average interobserver agreement was $92.2 \%$ (range: $86 \%-100 \%)$. The pre- and posttest was regraded separately by the first two authors. The outcome for re-grading reliability was $100 \%$. For time to complete the racetrack the smaller amount of seconds was divided by the larger and multiplied by 100 . Reliability for time to complete the math racetrack was $100 \%$.

\section{RESULTS}

\section{Number of Problems Correct}

The number of multiplication facts correctly answered during baseline and during DI flashcard and math racetrack procedures across three sets of basic multiplication facts for the student is shown in Fig. (1). The average number of correctly stated multiplication facts during baseline for Set 1 was 0.0 out of 7 . After implementation of the DI flashcard and math racetrack procedures, the number of correctly stated multiplication facts increased to a mean of 4.7 (range: 2 to 7 ). The baseline average for Set 2 was 1.75 (range: 1 to 3 ) out of 7, which increased to an average of 5.1 (range: 3 to 7) for the intervention. The baseline average for Set 3 was 0 out of 7. It increased to an average of 5.5 math facts correct (range: 4 to 7 ) when DI flashcards and a modified racetrack was in effect.

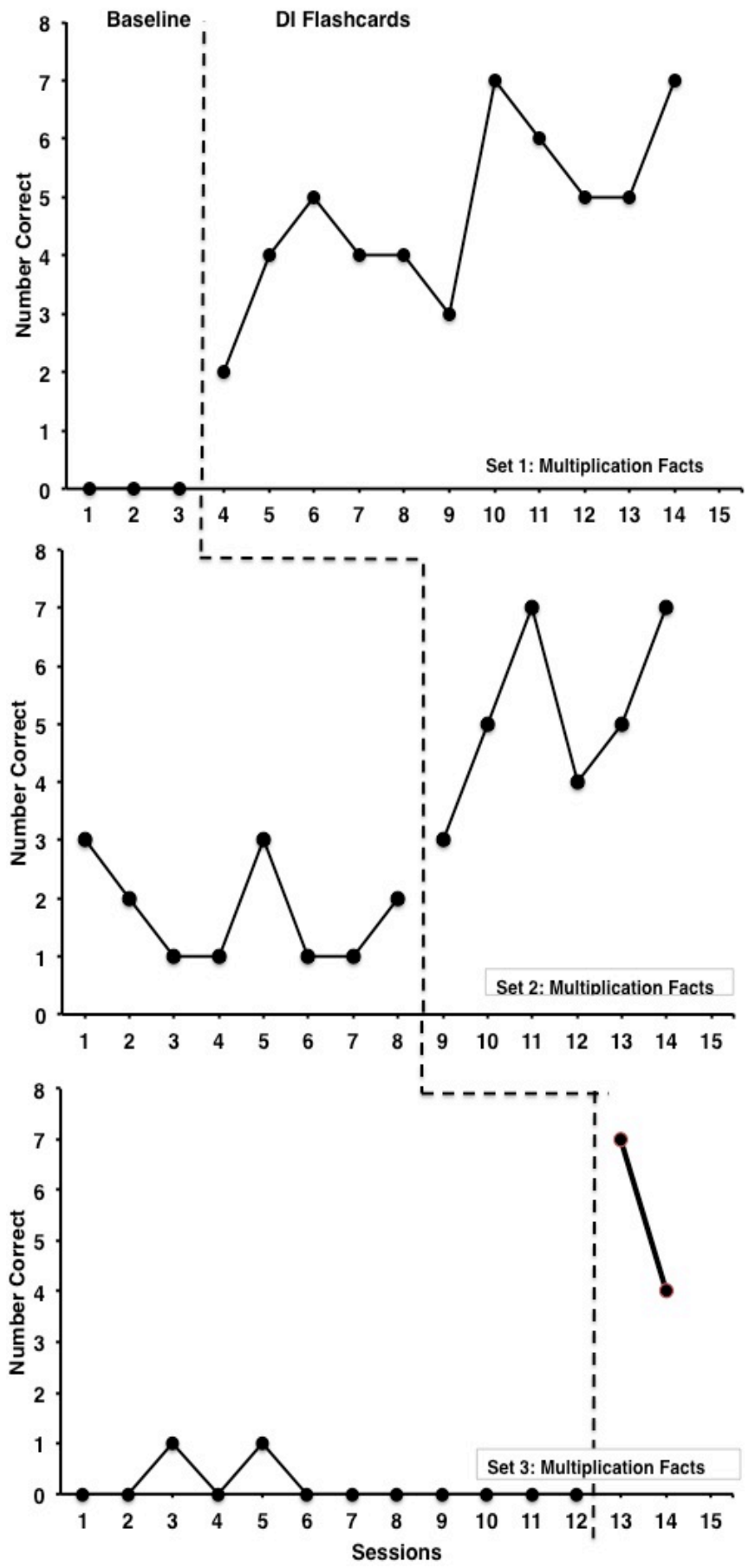

Fig. (1). The number of math facts correct during baseline and DI flashcards with a math racetrack.

\section{Time to Complete the Racetrack}

The initial time for the math racetrack, which contained Set 1 with mastered facts, was 39 seconds, which decreased to 27 seconds during the intervention (see Fig. 2). The initial time for the math racetrack, which contained Set 2 items and review problems from Set 1, was 35 seconds, which decreased to 28 seconds by the end of data collection. The initial time for the math racetrack, which contained Set 3 and review items of Set 2, was 50 seconds, which decreased to 38 seconds by the end of the project. 


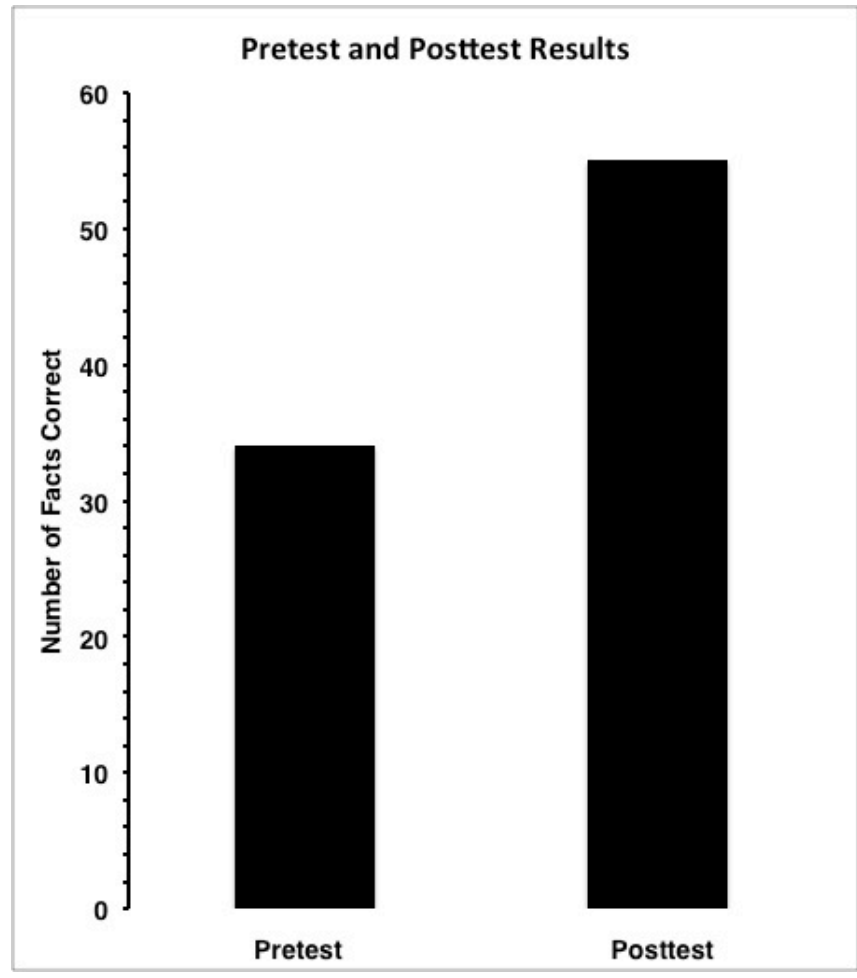

Fig. (2). The number of math facts correct for pre- and post-testing for our participant.

\section{Pretest and Posttest Outcomes}

The 100-problem basic-multiplication fact pretest score was 34 correct facts. This increased to 55 correct facts on the posttest. This was an improvement of $162 \%$.

\section{DISCUSSION}

The use of the DI flashcards and math track was sufficiently effective in improving a $6^{\text {th }}$ grade girl's multiplication facts. Our participant made large increases in saying correctly her basic facts. In addition to an increase in basic facts with the flashcards, she showed a large decrease in the time to complete her math track. Her improvement was correlated with the implementation of the intervention. Finally, her improvement on the posttest was clearly evident.

The present research provides an additional replication as to the efficacy of DI flashcards and a math racetrack. In this case report, these procedures could be implemented and evaluated in the private school special classroom setting. It also extends our prior research in the public schools $[8,19$, $22]$ to a parochial school in the same region of the county. In addition this supports the use of such academic practice procedures for students having difficulty in math $[25,26]$.

The effects of the DI flashcards and math racetrack were meaningful and socially significant for our participant. Her performance not only increased, but according to her classroom teacher, so did her motivation and confidence in her math class. When the first two authors first started working with her she was hesitant to work with them. She indicated that she felt she was being singled out from the rest of her class. She once stated, "I don't like working with you because I don't know my facts and its embarrassing." As the intervention progressed along with her performance, she was excited to work with the researchers and excited about working with the flashcards and racetrack. The researchers noticed a significant change in her demeanor. She began to set up straight and smiled more often. When asked, "Why do you think we are working with you?" She responded, 'I am working with you to improve my times facts.' When she was shown her improvement on a graph, she noting that she was proud and appreciative of the intervention and work she had completed. When asked, "How well do you think you did at learning the multiplication facts?" She said, 'Pretty well, and I feel a lot more confident with my facts than when we started.' And when asked "How much do you like the flashcards compared to the racetrack?" she said, 'I like the racetrack because it goes really fast and makes me feel like I know them really well but the flashcards helped me learn more.' This validates the meaningfulness and social significance of this intervention procedure.

There were limitations to the present case report. First, we only employed a single student. Second, data collection was limited in duration due to the time required to place the first two authors in the classroom and the amount of weeks left in the semester. Unfortunately, this issue only allowed 14 school days for actual data collection and instruction. The outcomes for Set 2, indicated that there were two overlapping data points between the intervention and baseline. Finally, it would have been a nice to evaluate the efficacy of DI flashcards and the math racetrack had the accuracy for our participant's daily assignments in math. However, this was not possible.

The DI flashcard and math racetrack procedures were practical to implement and carry out. The first two authors did not have to spend a large amount of time, as they could only work with the participant every Tuesday and Thursday for about 20 minutes. This not only demonstrates the possible effectiveness of these procedures, but it should not require a great deal of any classroom time. The procedure was very inexpensive, almost cost-free, as the flashcards were provided by the researchers' professor and can be hand made at no expense. The math racetrack was also easy to construct. This proved to be an easy way to construct our modified racetrack. Training was minimal as this procedure was taught in the third author's class in applied behavior analysis and in direct meetings with him. Training was completed in 30 minutes. Finally, the math racetrack took less and less times as the first two authors arranged the multiplication flashcards in rows on a desk. Overall, we were very pleased with the outcome and improvements demonstrated by the student.

To maintain the DI flashcard and math racetrack procedure we gave a copy of the data and procedures to the student's classroom teacher. The first two authors also taught the student to use the flashcards and math racetrack on her own. The first two authors made an additional set of flashcards for the student with the same 21 target facts for the student to work with independently. Our participant was taught to move the flashcard two cards back if she answered incorrectly and to move the card to the back of the deck if she answered correctly.

\section{AUTHOR NOTES}

This research was completed for the partial fulfillment of requirements for the course, Applied Behavior Analysis in 
the Department of Special Education at Gonzaga University. The authors would like to give thanks our participant, her parents, and the cooperating teacher for allowing us to complete this study. The fifth author has finally retired from all classroom teaching and is enjoying his retirement by traveling, playing golf, and enjoying his other hobbies.

\section{CONFLICT OF INTEREST}

The authors confirm that this article content has no conflict of interest.

\section{ACKNOWLEDGEMENTS}

Declared none.

\section{REFERENCES}

[1] Lloyd DN. Prediction of school failure from third-grade data. Educ Psychol Meas 1978; 38: 1193-200.

[2] Silbert J, Carnine DW, Stein M. Direct instruction mathematics. Columbus, OH: Charles E. Merrill 1981.

[3] Polya G. The goals of mathematical education. Math Teaching 2002; 181: 6-44.

[4] Stein M, Kinder D, Silbert J, Carnine DW. Designing effective mathematics instruction: a direct instruction approach. $4^{\text {th }}$ ed. Upper Saddle River, NJ: Pearson Education 2006.

[5] Johnson KR, Layng TV. The morning side model of generative instruction. In: Gardner R, Sainato DM, Cooper JO, et al., Eds. Behavior analysis in education: focus on measurably superior instruction. Pacific Grove, CA: Brooks/Cole 1994; pp. 173-97.

[6] Stood, S, Jitendra AA. comparative analysis of a number sense instruction in reform-based and traditional mathematics textbooks. J Spec Educ 2007; 41: 145-57.

[7] Heward WL. Exceptional children: an introduction to special education. $10^{\text {th }}$ ed. Upper Saddle River, NJ: Prentice-Hall/Pearson Education 2012.

[8] Cai, J. Improving mathematics learning: lessons from cross-national studies of Chinese and U.S. students. Phi Delta Kappan 2007; 82: 400-4.

[9] Adams G, Carnine D. Direct instruction. In: Swanson HL, Harris KR, Graham S, Eds. Handbook of learning disabilities. New York, NY: Guilford Press 2002: pp. 403-16.

[10] Kinder D, Carnine D. Direct instruction: what it is and what is it becoming. J Behav Educ 1991; 1: 193-213.

[11] McLaughlin TF, Weber KP, Derby KM, et al. The use of a racetracks procedure to improve the academic behaviors of students in special and remedial education: suggestions for school personnel. In: Demir O, Celik C, Eds. Multimedia in education and special education (2 volume set). Columbus, $\mathrm{OH}$ : Nova Science Publishers 2011; pp. 95-111.

[12] Rinaldi L, McLaughlin TF. The effects of reading racetracks on the fluency of see-to-say words in isolation by a student with learning disabilities. J Precis Teach Celeration 1996; 13(2): 44-52.

[13] Rinaldi L, Sells D, McLaughlin TF. The effects of reading racetracks on sight word acquisition and fluency of elementary students. J Behav Educ 1997; 7: 219-33.
[14] Green C, McLaughlin TF, Derby KM, Lee K. Using reading racetracks and flashcards to teach sight words to students with disabilities: effects for acquisition and response maintenance. J Educ Res 2010; 13(2): 84-98. Retrieved from: http://www.iub.edu. $\mathrm{pk} / \mathrm{jer} / \mathrm{previous}$ issue.html

[15] Kaufman L, McLaughlin TF, Derby KM, Waco T. Employing reading racetracks and DI flashcards with and without cover, copy, and compare and rewards to teach of sight words to three students with learning disabilities in reading. Educ Res Q 2011; 34: 24-44.

[16] McGrath G, McLaughlin TF, Derby KM, Bucknell W. The effects of using reading racetracks for teaching of sight words to three third-grade students with learning disabilities. Educ Res Q 2012; 35(3): 50-66.

[17] Glover P, McLaughlin TF, Derby KM, Gower J. Using a direct instruction flashcard system employing a back three contingency for errors with two students with learning disabilities. Electron J Res Educ Psychol 2010; 8(2): 457-82. Retrieved from http://www.i nvestigacion-psicopedagogica.org/revista/new/english/anteriores.php

[18] Lund K, McLaughlin TF, Neyman J, Everson M. The effects of DI flashcards and math racetrack on multiplication facts for two elementary students with learning disabilities. J Spec Educ Apprenticeship 2012; 1(1): 1-15. http://josea.info/index.php?page= vollno1

[19] Pfaff E, McLaughlin TF, Neyman J, Everson M. The effects of direct instruction flashcards with math racetrack with addition facts for an elementary school student with ADHD. Int J Basic Appl Sci 2013; 2(1): 124-130. Retrieved from: http://www.insikapub.com/

[20] Pierce K, McLaughlin TF, Neyman J, King K. The gradual and differential effects of direct instruction flashcards with and without a DRH contingency on basic multiplication facts for two students with severe behaviors disorders. J Educ Psychol 2012; 6(2): 35-44. Retrieved from: http://www.imanagerpublications.com/Archives.a $\operatorname{spx}$

[21] Skarr A, Zielinski K, Ruwe K, Sharp H, Williams RL, McLaughlin TF. The effects of direct instruction flashcard and math racetrack procedures on mastery of basic multiplication facts by three elementary school students. Educ Treat Child 2014; 37: 77-93.

[22] McLaughlin TF, Williams BF, Williams RL, et al. Behavioral training for teachers in special education: The Gonzaga University program. Behav Intervent 1999; 14: 83-134.

[23] Kazdin AE. Single case research designs: methods for clinical and applied settings. $2^{\text {nd }}$ ed. New York: Oxford University Press 2011

[24] McLaughlin TF. An examination and evaluation of single subject designs used in behavior analysis research in school settings. Educ Res Q 1983; 7: 35-42.

[25] Mann Z, McLaughlin TF, Williams RL, Derby KM, Everson M. The effects of direct instruction flashcards and rewards with math facts at school and in the home: acquisition and maintenance. J Spec Educ Apprenticeship 2012; 1(2). Retrieved from: http://josea.info/index.php?page $=$ archives

[26] Brasch TL, Williams RL, McLaughlin TF. The effects of a direct instruction flashcard system on multiplication fact mastery by two high school students with ADHD and ODD. Child Fam Behav Ther 2008; 30: 51-9. 